\title{
Patient satisfaction survey for HAM-net registrants
}

\author{
Kentaro Sato ${ }^{1 *}$, Takayuki Kikuchi ${ }^{1}$, Miyuna Kimura ${ }^{1}$, Midori Komita ${ }^{1}$, Kanade Shimada ${ }^{1}$, Krumi Seki ${ }^{1}$, \\ Marika Tachibana', Naoko Yagishita², Ariella Coler-Reilly², Tomoo Sato², Natsumi Arayta², Miho Ishikawa², \\ Mikako Koike ${ }^{2}$, Yumi Saito ${ }^{2}$, Hiroko Suzuki ${ }^{3}$, Ayako Takata ${ }^{4}$, Yoshihisa Yamano ${ }^{2}$
}

From 17th International Conference on Human Retroviruses: HTLV and Related Viruses

Trois llets, Martinique. 18-21 June 2015

Patient registries can foster communication between doctors and patients who have rare diseases. In order to succeed in the long term, the managers of the registry must work to raise the satisfaction of the registrants. We conducted a satisfaction survey for the HTLV-1 associated myelopathy (HAM) patient registry known as "HAM-net." Based on the data we collected, we made several alterations, mainly to the newsletter and website. This year we repeated the survey to determine if our alterations were beneficial or not by assessing changes in satisfaction levels. We surveyed 368 patients registered to HAM-net, inquiring about their general impression of HAM-net, the requisite telephone interviews, the newsletter, and the website. The response rate was $74.7 \%$, and 198 registrants responded to the satisfaction survey both times. The number of individuals satisfied with HAM-net in general improved from $63.6 \%$ to $77.3 \%$ of registrants. More specifically, satisfaction with the newsletter rose dramatically but no significant change was observed for the website. Therefore we concluded that focusing on the newsletter is currently the best way to improve patient satisfaction. For example, we deduced that it is beneficial to increase the volume and quality of the articles. On the other hand, we could not demonstrate that frequently updating the website was beneficial to the patients. We inferred that the website must be improved to be more appealing and useful to the patients. In this study, we showed that properly investigating patient satisfaction using a detailed questionnaire can produce the data necessary to improve patient satisfaction levels. The best way to preserve a good relationship with the registered patients in the

${ }^{1}$ St. Marianna University School of Medicine, Kawasaki, Kanagawa, 2168511, Japan

Full list of author information is available at the end of the article long term is to prioritize understanding the patients' needs and continuously work to improve their satisfaction.

\section{Authors' details}

${ }^{1}$ St. Marianna University School of Medicine, Kawasaki, Kanagawa, 2168511, Japan. ${ }^{2}$ Department of Rare Diseases Research, Institute of Medical Science, St. Marianna University School of Medicine, Kawasaki, Kanagawa, 2168511, Japan. ${ }^{3}$ Intractable disease Consultation, St. Marianna University School of Medicine, Kawasaki, Kanagawa, 2168511, Japan. ${ }^{4}$ Department of Preventive Medicine, St. Marianna University School of Medicine, Kawasaki, Kanagawa, 2168511, Japan.

Published: 28 August 2015

\section{doi:10.1186/1742-4690-12-S1-P40}

Cite this article as: Sato et al:: Patient satisfaction survey for HAM-net registrants. Retrovirology 2015 12(Suppl 1):P40.

\author{
Submit your next manuscript to BioMed Central \\ and take full advantage of: \\ - Convenient online submission \\ - Thorough peer review \\ - No space constraints or color figure charges \\ - Immediate publication on acceptance \\ - Inclusion in PubMed, CAS, Scopus and Google Scholar \\ - Research which is freely available for redistribution

C Biomed Central

(c) 2015 Sato et al. This is an Open Access article distributed under the terms of the Creative Commons Attribution License (http:// creativecommons.org/licenses/by/4.0), which permits unrestricted use, distribution, and reproduction in any medium, provided the original work is properly cited. The Creative Commons Public Domain Dedication waiver (http://creativecommons.org/publicdomain/ zero/1.0/) applies to the data made available in this article, unless otherwise stated. 